\title{
What it's like to be an editor at a conference
}

\author{
Chris Gunter
}

Scientific conferences: when you start out as a graduate student, you most likely get to go to the big one in your field each year, and maybe a local symposium. As a postdoc, you might add one or two more. At any of these, you are likely to run into either academic or professional journal editors.

It's tempting as a scientist to believe that many editors are like Scrooge in A Christmas Carol, pre-Ghost visits. Instead, most subscribe to the later, 'there is nothing in the world so irresistibly contagious as laughter and good humour' philosophy from the Dickens book. Editors know just like you that the scientific conference is a great place to merge the best research and good humor (particularly in the bar).

As a manuscript editor at Nature, I regularly went to 6 to 10 conferences a year, in addition to many lab visits around the world. I quickly realized that travel and meeting authors in person was one of the best ways to learn what authors want from editors, while also being one of the best ways to keep me from doing the rapid yet thoughtful manuscript handling that authors say is their top priority. I've broken the experience of being a professional editor at a conference into three groups of authors: past, present and future.

1. Authors past. Let's face it: rejection stinks all around. Legend attributes this nugget to Benjamin Lewin, founder of Cell: 'Everyone thinks that my job is publishing papers. In reality, my job is rejection of papers.' Over my 6.5 years at Nature and on average turning up to $80 \%$ of submissions away without review, the constant sending of rejection letters became the worst part of the job.

Predecessors taught me to implement a 24-hour rule; that is, not taking any calls from rejected authors until the next day. This makes a huge difference in the tone of the interaction, giving everyone a chance to sleep on things (and thus I still use it as a general policy when I find myself on the author side). Unfortunately, at conferences people with understandably hurt feelings may be thrown together in small spaces.

Correspondence: drchrisgunter@gmail.com

Girlscientist Consulting, Atlanta, GA 30033, USA
My worst experience came at a model organism conference. We had reviewed a paper from a team of authors, and the review process had just not gone well. Referees had dropped out, and the two reviews I finally received after weeks of cajoling and pleading were not as helpful as I'd like. The team discussed the situation and data and decided to decline publication of the paper based on these two reviews and our own research of the area. To me, it felt terrible. I included in the letter several apologies for the delay in the process and indicated that I would be happy to discuss the decision with the authors at any time, including the conference that was the next week.

A significant fraction of a professional editor's job boils down to customer service, and you quickly learn that if you make customers unhappy, they will tell as many people as possible. At the conference, I went up and introduced myself to the senior author, as I had promised. He said 'Oh! It's you. Oh boy, there is someone you have GOT to meet.' So he took me over to the first author and said 'Look who's here! She even had the nerve to come up and introduce herself' Not a good sign. I offered my apologies again for the process, and restated that I would be glad to discuss with them what had happened and how the team had reached their decision. Rather than scientific discussion, I received ten minutes of them both, aiming for the entire room to hear, stating loudly among other things that I had 'ONE JOB, which was to MANAGE THE PEER REVIEW PROCESS' and that I was 'CLEARLY UNABLE TO EVEN DO THAT.'

We all get angry and upset when things don't go well, and I would not say that these authors were wrong in this case - there was an imperfect storm of bad circumstances, and I'd had to make a very tough call. Yet, I would encourage you to pursue a more nuanced path in your next steps after receiving a negative decision. For many authors whose papers I'd unfortunately had to reject, what followed were constructive conversations about revisions or next options for submission.

Use editors as a resource. They are familiar with what other journals are looking for, and can even offer contact info for the best person for you to speak with at the next journal. They've often seen papers similar to yours, and 
can tell you where they think the paper might fit best or sometimes even if they have heard of a competing paper somewhere else. They can't discuss papers they have under review, but each journal has its own policies on what to do if your work is similar to a submission they are currently reviewing.

And, although this is difficult when emotions run high, do keep in mind that rejection of a paper pertains only to that specific paper. My postdoc mentor repeatedly told me that 'building a scientific career is all about relationships,' so think about the long term and beyond the current interaction. You have another great project that you think would fit in the editor's journal? Tell them about it. You have a conference or event coming up and could use some publicity? Tell them about that too. Professional editors are constantly asked what's going on in their field, and they can help you spread the word.

On the bright side: at conferences, editors also meet past authors whose papers they have published. Generally, these authors say nicer things!

2. Authors present. At every conference she or he attends, an editor is walking around with a database whirring in their head, constantly checking the name of each person they run into against the ongoing or past submissions they have handled from that person. The mental database is also crosschecking badges against the referee reports which are overdue - which, of course, is at least half the attendees for one journal or another.

If you have a submission with an editor, by all means, ask them to discuss it at the conference. They will not have the referee reports or team discussion in front of them, so they may not be able to tell you too much. But you will definitely learn more about the status than the frustrating one-liners you get from the online submission system. When I give talks on the publication process even today, one of the top questions is always 'When am I allowed to inquire about my paper?!'

Legend also has it that back in days of yore, one chief editor of Nature had twelve stacks of papers on a windowsill in his office. Every time someone wrote to ask about his or her submission, according to myth, he moved the paper over one stack toward the pile under current consideration. Things have changed slightly - but do keep in mind that a polite email about the status of your paper is always your right. Good editors have no reason to punish anyone for asking, nor do they focus only on the squeaky wheels.

My rules of thumb for appropriate query times when you have not heard anything at all: five days for a presubmission enquiry (particularly at larger journals with professional editors), 10 days for a new submission, and 30 days for a manuscript at review. These are based on processing times for life sciences papers at the journals I've had experience with, so your mileage may vary. Unless you get an email explicitly telling you that a submission has gone out to review, do not assume that it has.

You may be one of those referees with overdue reports. Although editors are pushy and demanding of your services in a short timeframe, and they forget to tell you this because we are all overworked: they are truly grateful for your insight and contributions.

3. Authors yet to come. This part can be the most fun of any conference. A great point for an editor is when authors actually start approaching her or him with ideas for possible submissions. Count yourself among these potential authors, especially at smaller conferences when you are all thrown together on the bus to that day's outing.

Alternatively, editors may approach you after your talk and ask if you would consider submitting to their journal. Well done! Keep in mind there is a difference between the professional editor and the press, and I'll deal with the latter in a moment. You should consider the journal editor as someone who is not a reporter and will not 'leak' any of your story publicly. The last thing they want is to turn over your data or ideas to the competition before publication. If you are interested in publishing in that journal, then you should indicate so; you are under no obligation until all parties have agreed and you have formally submitted the paper, of course. (But don't be that person who submits their manuscript to multiple journals at once and then withdraws it from all the others once you get into review at one place. No one likes that person.)

If a journalist or reporter approaches you at a conference and wants to write about your unpublished work, you should think carefully about the options. For years, many journals have had the policy that you are allowed to talk at scientific conferences all you would like, but you should not speak to the press about your work before it is published. This is called the Ingelfinger rule (http://www. nejm.org/doi/full/10.1056/NEJM198110013051408), and Ivan Oransky at Retraction Watch has written several nice blog posts (http://embargowatch.wordpress.com/2010/06/ 18/its-not-just-the-ingelfinger-rule-scientists-dont-want-otherscientists-scooping-them-either/; http://embargowatch. wordpress.com/2013/08/22/scientists-like-the-gag-orderof-the-ingelfinger-rule-says-new-paper/) about the paradox of scientists supporting this rule that impedes dissemination of their own work.

Times are changing, and it's becoming more common for biologists to post preprints of their work online well before publication, just as physicists have done for years at the arXiv database (http://arXiv.org). In evolutionary genetics, the Haldane's Sieve website (http://haldanessieve. org/) has become a home for posting and annotating of preprints before submission for formal peer review even. Shortly, Cold Spring Harbor Laboratory plans to launch bioRxiv (http://bioRxiv.org) as a home for biology preprints, with citability and versioning for contributions 
(disclosure: I am on the executive group). Recently, Nature featured a news story on a paper that had only been published as a preprint on arXiv (http://www.nature. com/news/african-genes-tracked-back-1.13607), and many journals, including Genome Biology, have said they will not consider preprints online to be an impediment to consideration of a work for publication.

Again, consider the options and consult the journal to which you are planning on submitting before talking to any reporters if you think there may be any issues. Given the explosion of blogging and social media, the definition of 'press' is blurring, and one can foresee that the role of an editor will continue to change as well. As long as the scientific community values the filtering function and improvement of final published units that editors can provide, they will still be around in some form, and are likely to be at the next conference you attend.

Published: 31 October 2013

doi:10.1186/gb4136

Cite this article as: Gunter: What it's like to be an editor at a conference. Genome Biology 2013 14:136. 